\title{
Age, period and cohort effects on body weight and body mass index in adults: The Doetinchem Cohort Study
}

\author{
Astrid CJ Nooyens ${ }^{1,2, *}$, Tommy LS Visscher ${ }^{1,2}$, WM Monique Verschuren ${ }^{1}$, A Jantine \\ Schuit ${ }^{1,2}$, Hendriek C Boshuizen ${ }^{1}$, Willem van Mechelen ${ }^{3}$ and Jacob C Seidell ${ }^{2,3}$ \\ 'Division of Public Health, National Institute for Public Health and the Environment (RIVM), Antonie van \\ Leeuwenhoeklaan 9 PO Box 1, 3720 BA Bilthoven, The Netherlands: ${ }^{2}$ Institute of Health Sciences, VU \\ University, Amsterdam, The Netherlands: ${ }^{3}$ EMGO Institute, VU University Medical Center, Amsterdam, \\ The Netherlands
}

Submitted 5 0ctober 2007: Accepted 3 April 2008: First published online 24 July 2008

\begin{abstract}
Objective: To study the development of body weight with ageing, in a general adult population, taking into account possible period and cohort effects.

Design: A prospective cohort study with 11 years of follow-up. At baseline and after 6 and 11 years, body weight and height were measured.

Setting: The Doetinchem Cohort Study, consisting of inhabitants of Doetinchem, a town in a rural area of The Netherlands.

Subjects: In total, 4070 healthy men and women aged 20-59 years at baseline. Results: Increase in BMI with ageing was less profound based on cross-sectional data than based on longitudinal data. More recent-born cohorts had a higher BMI at a given age than cohorts who were born earlier. Increase in mean BMI with ageing was observed in all age groups and was similar for groups with a different educational level. Highest increase in BMI over 11 years was observed in the youngest group, aged 20-29 years at baseline $\left(2 \cdot 2[95 \%\right.$ CL $\left.2 \cdot 0,2 \cdot 3] \mathrm{kg} / \mathrm{m}^{2}\right)$, and lowest increase in the oldest group, aged $50-59$ years at baseline $\left(1 \cdot 1[1 \cdot 0,1 \cdot 3] \mathrm{kg} / \mathrm{m}^{2}\right)$. Conclusions: Findings of the present study using longitudinal data suggest that increase in BMI with ageing is underestimated in all age groups by studying crosssectional data only. Further, weight gain is present in all educational levels and does not stop at middle age.
\end{abstract}

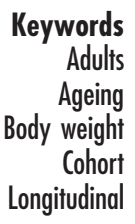

It is often observed that levels of BMI and prevalence of obesity increase with age until age 60-70 years and decline thereafter. These observations are usually based on crosssectional studies ${ }^{(1-5)}$. However, such age-BMI relationships may result from mixed effects of ageing per se, characteristics of subsequent birth cohorts and selective survival. Studies based on successive cross-sectional surveys show that younger birth cohorts have a higher mean BMI at the same age compared to older cohorts ${ }^{(2,6-10)}$, and that the prevalence of overweight and obesity increases over time, independent of age ${ }^{(11-15)}$.

Increases in BMI with ageing in cross-sectional studies may be the result of age and cohort effects, while increases in BMI with ageing in longitudinal studies may include period effects. Age effects on body weight and BMI are due to behavioural and physiological changes within individuals ${ }^{(16)}$ that occur as a result of ageing, e.g. the lowering in energy requirement at rest with ageing. Period effects are due to population-wide changes in behaviours and other exposures among individuals independent of ageing ${ }^{(16)}$ during the study period and affect all birth cohorts simultaneously, e.g. a change in legislation during the study period that promotes active transport. Cohort effects are influences of populationwide exposures that took place before the study period, e.g. secular differences in environment that may affect behaviour during later life. Disentangling age, period and cohort effects on BMI is crucial to assess future trends in BMI and accompanying health disorders ${ }^{(17)}$.

Evaluation of age, period and cohort effects on BMI requires longitudinal assessment with repeated measures in the same individuals. There are only a few studies that allow this evaluation. We found four studies that have evaluated age and/or cohort effects on BMI on longitudinal data in recent time periods. These studies show that people who are born later have higher BMI at the same attained age ${ }^{(18,19)}$ and that younger people gain more weight as they become older compared to older people $\mathrm{e}^{(18-21)}$. These studies were conducted on data from either only young (18-30 years) ${ }^{(20)}$ or middle-aged (45-64 years $)^{(18)}$ adults, based on self-reported data on body weight $^{(19,21)}$, or in one gender only ${ }^{(19)}$. 
In the present study, impact of age, period and cohort effects on BMI will be evaluated in the Doetinchem Cohort Study (DCS). This is a population-based cohort study in The Netherlands, in which subjects aged 20-59 years at baseline are followed over a period of 11 years between 1987-1991 and 1998-2002. For all subjects, body height and weight were measured by trained staff.

\section{Methods}

\section{Sample}

Based on an age- and sex-stratified sample survey from the civil registries of the Dutch town Doetinchem, 20155 inhabitants aged 20-59 years were invited to visit the municipal health centre to participate in the 'Monitoring Project on Cardiovascular Disease Risk Factors' between 1987 and $1991^{(22)}$. From the participants in this first examination ( $n 12405$, participation rate $62 \%$ ), a random sample of 7769 was invited for a second examination (1993-1997) for budgetary reasons ${ }^{(23)}$. This random sample is considered as the basis for the prospective DCS. Participants who actively refused to participate in the second examination were not invited for the third examination (1998-2002). In the second examination, 6118 subjects were examined (participation rate $79 \%)^{(24)}$ and 6579 participants were again invited for a third examination between 1998 and 2002, of whom 4917 were examined (participation rate $75 \%$ ). The cohort profile of the DCS is described in detail elsewhere ${ }^{(23)}$.

In total, 4636 subjects fully completed all three examinations. For the purpose of the present study, subjects who suffered from cancer ( $n$ 220), diabetes ( $n$ 117) and/ or CVD ( $n$ 158) were excluded, as were women who reported to be pregnant during any of the examinations ( $n$ 116). This left a total of 4070 subjects, 1988 men and 2082 women, for the present study.

\section{Measures}

Body weight and height were measured at the municipal health centre at all three examinations, wearing light indoor clothing with emptied pockets and without shoes. Height was measured with a wall-mounted stadiometer to the nearest $0.5 \mathrm{~cm}$. Body weight was measured with a balance beam scale to the nearest $0.5 \mathrm{~kg}$. To adjust for light indoor clothing, $1 \mathrm{~kg}$ was subtracted from the measured weight. BMI was calculated as weight divided by height squared $\left(\mathrm{kg} / \mathrm{m}^{2}\right)$.

Demographic characteristics and medical history of chronic diseases were collected using standardized questionnaires $^{(24)}$, by which also educational level and smoking status were recorded. Educational level was assessed as the highest level of completed education at follow-up and classified into three categories: low (intermediate secondary education or less), moderate (intermediate vocational or higher secondary education) and high (higher vocational education or university). Smoking status was defined as being a non-smoker (i.e. smoking less than one cigarette per month), an exsmoker or a smoker at the time of measurement, based on a question about current cigarette smoking. Neversmokers were defined as subjects who reported to be a non-smoker at all three examinations. We have no information on country of birth or ethnicity per se, but we do have information on nationality. Since over $98 \%$ of the participants were Dutch, we did not take nationality into account in our analyses.

\section{Analyses}

To evaluate age, period and cohort effects on BMI, four approaches were used.

\section{Cross-sectional approach}

The mean BMI of subjects in 10-year age groups was compared within the cross-sectional surveys. In these analyses, age groups (20-29, 30-39, 40-49, 50-59 and 60-69 years) were not included when the range of the age group was not full within the survey, e.g. the age group 20-29 years was not included in the second measurement round, since the youngest participants were aged 26 years. In the figures based on this (multiple) cross-sectional approach, average BMI in the 10-year age groups within the measurement rounds was plotted by the measurement round.

\section{Time series}

The mean BMI of subjects within the 10-year age groups was compared across periods. In these analyses, age groups were only included when all ages within the range of the age group (20-29, 30-39, 40-49, 50-59 and 60-69 years) were present in all three surveys, with one exception: the youngest age group in 1998-2002 was aged 31-39 years.

\section{Longitudinal approach}

The mean BMI of subjects within different cohorts was followed over time using longitudinal data. This third approach was also applied for mean body weight. Cohorts were defined based on age at baseline (20-29, 30-39, 40-49 and 50-59 years). In the figures based on this longitudinal approach, average BMI or body weight in these four cohorts was plotted against the average age in the cohorts during the measurements.

\section{Random intercept models}

In order to quantify the independent associations of age, period and cohort with BMI, random intercept model analyses were used. BMI and age were entered as continuous variables. Period (baseline, 6 and 11 years followup) and cohort (age groups at baseline: 20-29, 30-39, 40-49 and 50-59 years) were entered as categorical variables. First, age and period were related to BMI, 
representing a cross-sectional perspective. Second, age and cohort were related to BMI, representing a longitudinal perspective. In these models, age was entered as both a linear and a quadratic term, to take into account a potentially exponential relationship between age and BMI. If the quadratic term was not statistically significant (two-sided at $P=0 \cdot 10$ ), it was excluded from the model. To evaluate potential differences in BMI development with age within different periods, an interaction term of age and period was entered in the age-period model. To evaluate potential differences in BMI development with age for different birth cohorts, an interaction term of age and cohort was entered in the age-cohort model. If these interaction terms were not statistically significant (twosided at $P=0 \cdot 10$ ), they were excluded from the model.

The increase in BMI with ageing, adjusted for, respectively, period and cohort effects, was plotted. For these figures, the average BMI level of the group aged 20-29 years in 1987-1991 was used as the reference point for the intercept at age 20: BMI $23 \cdot 4 \mathrm{~kg} / \mathrm{m}^{2}$ for men and BMI $22.5 \mathrm{~kg} / \mathrm{m}^{2}$ for women.

All analyses were carried out for men and women separately. Analyses on longitudinal data were additionally stratified for the level of education in order to study potential influences of the level of education on changes in BMI with ageing. Differences in (changes in) BMI between the different levels of education were tested by analyses of variance at $P=0 \cdot 05$. Analyses on longitudinal data were also performed for never-smokers only, in order to study changes in BMI with ageing independent of influences of (changes in) smoking behaviour. All analyses were carried out using SAS version 9·1 (SAS Institute Inc., Cary, NC, USA).

\section{Results}

At baseline, mean age was $39 \cdot 8$ years and mean BMI was $24.4 \mathrm{~kg} / \mathrm{m}^{2}$. In total, $37 \cdot 9 \%$ of the participants had a BMI $\geq 25 \mathrm{~kg} / \mathrm{m}^{2}$ and $5 \cdot 0 \%$ had a BMI $\geq 30 \mathrm{~kg} / \mathrm{m}^{2}$. After 11 years of follow-up, the mean BMI had increased to
$26 \cdot 0 \mathrm{~kg} / \mathrm{m}^{2}$, and the prevalence of BMI $\geq 25$ and $\geq 30 \mathrm{~kg} /$ $\mathrm{m}^{2}$ to $57 \cdot 8 \%$ and $13 \cdot 1 \%$, respectively. Cumulative incidence of $\mathrm{BMI} \geq 30 \mathrm{~kg} / \mathrm{m}^{2}$ was $8 \cdot 3 \%$ and $9.7 \%$ over the 11-year follow-up period among men and women, respectively, and was highest for the men and women aged 50-59 years at baseline $(9 \cdot 5 \%$ and $14 \cdot 1 \%$ respectively). Overall, $31 \cdot 7 \%$ of the participants were smokers at baseline, at the second examination the proportion of smokers was $29 \cdot 3 \%$ and at the third examination it was $26.4 \%$. In older age groups, participants were less tall, were more often non-smokers, had more often a lower educational level and were more often overweight and obese than participants in the younger age groups (Table 1).

\section{Multiple cross-sectional data}

Mean BMI was higher in older age groups in all periods (Fig. 1), except for men aged 60-69 years, for whom the mean BMI was not different from the mean BMI of men aged 50-59 years in the period 1998-2002 (Fig. 1a).

\section{Time series}

When the mean BMI of the 10-year age groups was compared across periods, the mean BMI was higher in more recent periods for every age category and in both men and women (Table 2).

\section{Longitudinal data}

Highest increase in body weight and in BMI during the 11-year follow-up was observed in the youngest age category $\left(7 \cdot 3 \mathrm{~kg}\right.$ or $2 \cdot 1 \mathrm{~kg} / \mathrm{m}^{2}$ for men and $6.7 \mathrm{~kg}$ or $2 \cdot 2 \mathrm{~kg} / \mathrm{m}^{2}$ for women). Smallest increases in mean body weight and mean BMI was observed in the oldest group of adults, aged $50-59$ years at baseline $(2 \cdot 3 \mathrm{~kg}$ or $0.9 \mathrm{~kg} /$ $\mathrm{m}^{2}$ for men and $2.8 \mathrm{~kg}$ or $1.3 \mathrm{~kg} / \mathrm{m}^{2}$ for women over the 11-year follow-up period; Figs 2 and 3 ).

The mean BMI of subjects with the lowest educational level was always higher than the mean BMI of the highest educated subjects, except for young adult men (Fig. 4). The mean BMI of the moderate educational level was always in between the mean BMI of the lowest and

Table 1 General baseline characteristics of the study population

\begin{tabular}{|c|c|c|c|c|c|c|c|c|}
\hline \multirow[b]{2}{*}{ Age at baseline } & \multicolumn{2}{|c|}{ 20-29 years } & \multicolumn{2}{|c|}{ 30-39 years } & \multicolumn{2}{|c|}{$40-49$ years } & \multicolumn{2}{|c|}{$50-59$ years } \\
\hline & Men & Women & Men & Women & Men & Women & Men & Women \\
\hline$n$ & 332 & 365 & 667 & 706 & 619 & 630 & 370 & 381 \\
\hline Age (years), mean & $25 \cdot 6$ & $25 \cdot 5$ & $35 \cdot 1$ & $35 \cdot 0$ & $44 \cdot 2$ & $44 \cdot 1$ & $54 \cdot 3$ & $54 \cdot 4$ \\
\hline Height $(\mathrm{cm})$, mean & $182 \cdot 0$ & $168 \cdot 1$ & $180 \cdot 5$ & $166 \cdot 7$ & $178 \cdot 2$ & $165 \cdot 6$ & $176 \cdot 9$ & $164 \cdot 3$ \\
\hline Non-smokers* $(\%)$ & $63 \cdot 0$ & $64 \cdot 7$ & $65 \cdot 2$ & $66 \cdot 4$ & $67 \cdot 5$ & $70 \cdot 6$ & $77 \cdot 8$ & $78 \cdot 2$ \\
\hline \multicolumn{9}{|l|}{ Level of educationt } \\
\hline Low (\%) & $28 \cdot 6$ & $35 \cdot 1$ & $34 \cdot 6$ & $50 \cdot 6$ & $40 \cdot 2$ & $61 \cdot 7$ & $47 \cdot 6$ & $73 \cdot 0$ \\
\hline Moderate (\%) & $49 \cdot 4$ & $49 \cdot 0$ & $34 \cdot 3$ & $24 \cdot 9$ & $30 \cdot \overline{4}$ & $18 \cdot 6$ & $24 \cdot 3$ & $14 \cdot 2$ \\
\hline High (\%) & $22 \cdot 0$ & $15 \cdot 9$ & $31 \cdot 0$ & $24 \cdot 5$ & $29 \cdot 4$ & $19 \cdot 7$ & $28 \cdot 1$ & $12 \cdot 9$ \\
\hline Overweight $\left(25 \leq \mathrm{BMI}<30 \mathrm{~kg} / \mathrm{m}^{2}\right)(\%)$ & $24 \cdot 4$ & $12 \cdot 6$ & $36 \cdot 0$ & $21 \cdot 1$ & $48 \cdot 1$ & $28 \cdot 3$ & $50 \cdot 8$ & $42 \cdot 0$ \\
\hline Obesity $\left(\mathrm{BMI} \geq 30 \mathrm{~kg} / \mathrm{m}^{2}\right)(\%)$ & $1 \cdot 8$ & $2 \cdot 5$ & $3 \cdot 0$ & $3 \cdot 1$ & $5 \cdot 5$ & $7 \cdot 5$ & $6 \cdot 2$ & $10 \cdot 8$ \\
\hline
\end{tabular}

*Non-smoking in all three examinations.

tHighest attained level during follow-up. 
highest groups. The increase in BMI over the 11-year follow-up period was similar for all levels of education within cohorts, except for the group of men aged 30-39 years, in which the lowest educated men increased statistically significantly less in BMI than the highest educated men $\left(1.5\right.$ and $1.9 \mathrm{~kg} / \mathrm{m}^{2}$, respectively, over the
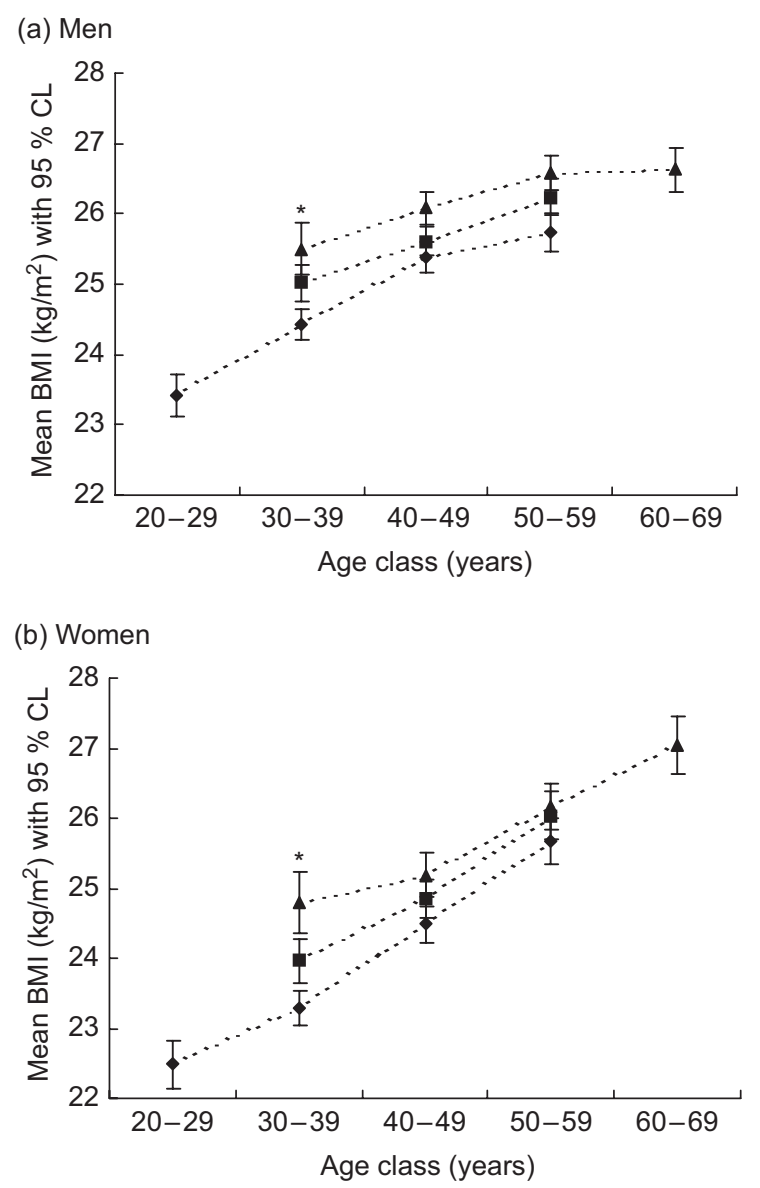

Fig. 1 Cross-sectional data of BMI in men (a) and women (b) in the three successive measurement rounds ( ....... 1987-1991; ......, 1993-1997; ......., 1998-2002): age and cohort effects (with a constant period). Values are means with their 95\% confidence limits (CL) represented by vertical bars; each line represents data from one measurement round. *Note that the youngest subjects in 1998-2002 were aged 31 years 11-year follow-up period, $P<0 \cdot 01$ ), and the men aged 50-59 years at baseline, in which the lowest educated men increased more in BMI than moderate educated and the highest educated men $(1.2 v .0 .7(P=0.04)$ and $0 \cdot 6 \mathrm{~kg} / \mathrm{m}^{2}(P<0 \cdot 01)$ respectively over the 11 -year followup period). Increase in BMI over time among neversmokers was similar to the increase observed for the total cohort (data not shown).

\section{Random intercept models}

The results of the mixed-model analysis for age and period in relation to BMI showed that the relationship between age and BMI was curvilinear ( $P$ for quadratic term $<0 \cdot 001$ ) for both men and women (Table 3 ). In men, the increase in BMI with ageing was similar over the periods. BMI increased $0 \cdot 8$ units from the first to the third period independent of age. In women, the increase in BMI with ageing was stronger in the first period and in younger women.

The results of the mixed-model analysis for age and cohort in relation to BMI also showed a curvilinear relationship between age and BMI. The increase in BMI with ageing was similar for all cohorts (no statistical significant interaction of age and cohort) and comparable for men and women (Table 3). Mean BMI at a given age was higher for more recent-born cohorts. The most recent-born cohort had a $2 \cdot 1$ units higher mean BMI at a given age in comparison to the cohort who was born 30 years earlier.

When modelling BMI as a function of age, independent of period (a 'cross-sectional' approach), the highest BMI was attained at age 58 years for men (Fig. 5a). In women, the highest BMI was not attained before age 70 years (Fig. 5b). Since there was an interaction between age and period in relation to BMI in women, the effects of age on BMI are displayed for each period separately. Based on the cross-sectional data, the increase in BMI with ageing in women was lower with later periods (Fig. 5b). When modelling BMI as a function of age, independent of cohort (a 'longitudinal' approach), BMI did not decline before age 70 years in both men and women (Fig. 5, black dots).

Table 2 Mean BMI $\left(\mathrm{kg} / \mathrm{m}^{2}\right)$ with $95 \% \mathrm{CL}$ of the mean for age groups across periods

\begin{tabular}{|c|c|c|c|c|c|c|c|c|c|}
\hline \multirow{2}{*}{$\begin{array}{l}\text { Age group during } \\
\text { measurement (years) }\end{array}$} & \multicolumn{3}{|c|}{ 1987-1991 } & \multicolumn{3}{|c|}{ 1993-1997 } & \multicolumn{3}{|c|}{ 1998-2002* } \\
\hline & $n$ & Mean & $95 \% \mathrm{CL}$ & $n$ & Mean & $95 \% \mathrm{CL}$ & $n$ & Mean & $95 \% \mathrm{CL}$ \\
\hline \multicolumn{10}{|l|}{ Men } \\
\hline 30-39 & 667 & $24 \cdot 43$ & $24 \cdot 22,24 \cdot 64$ & 488 & $25 \cdot 02$ & $24 \cdot 76,25 \cdot 27$ & 303 & $25 \cdot 50$ & $25 \cdot 15,25 \cdot 86$ \\
\hline $40-49$ & 619 & $25 \cdot 37$ & $25 \cdot 16,25 \cdot 59$ & 725 & $25 \cdot 61$ & $25 \cdot 40,25 \cdot 83$ & 656 & $26 \cdot 08$ & $25 \cdot 84,26 \cdot 32$ \\
\hline 50-59 & 370 & $25 \cdot 74$ & $25 \cdot 46,26 \cdot 02$ & 492 & $26 \cdot 23$ & $25 \cdot 98,26 \cdot 49$ & 642 & $26 \cdot 58$ & $26 \cdot 34,26 \cdot 82$ \\
\hline \multicolumn{10}{|l|}{ Women } \\
\hline 30-39 & 706 & $23 \cdot 29$ & $23 \cdot 04,23 \cdot 54$ & 549 & $23 \cdot 96$ & $23 \cdot 64,24 \cdot 27$ & 336 & $24 \cdot 79$ & $24 \cdot 35,25 \cdot 24$ \\
\hline $40-49$ & 630 & $24 \cdot 49$ & $24 \cdot 23,24 \cdot 75$ & 760 & $24 \cdot 84$ & $24 \cdot 57,25 \cdot 11$ & 692 & $25 \cdot 19$ & $24 \cdot 88,25 \cdot 50$ \\
\hline $50-59$ & 381 & $25 \cdot 64$ & $25 \cdot 31,25 \cdot 98$ & 458 & $26 \cdot 04$ & $25 \cdot 69,26 \cdot 38$ & 645 & $26 \cdot 16$ & $25 \cdot 84,26 \cdot 48$ \\
\hline
\end{tabular}

$\mathrm{CL}$, confidence limits.

${ }^{*}$ Note that in 1998-2002 the youngest participants were aged 31 years. 


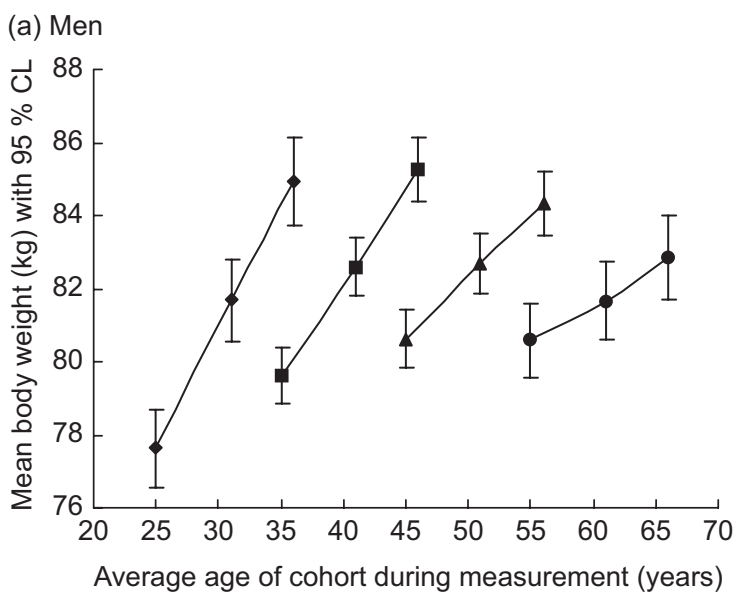

(b) Women

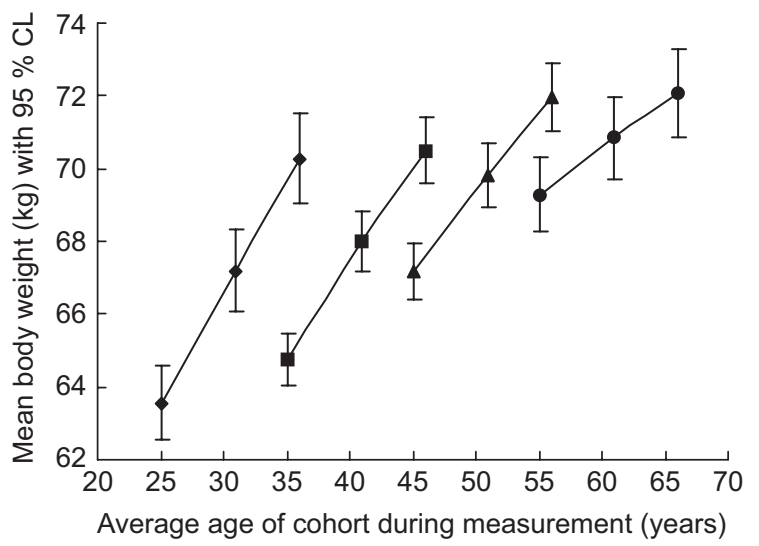

Fig. 2 Longitudinal data of (change in) body weight in men (a) and women (b) by age group $(\longrightarrow-, 20-29$ years; $\rightarrow-$, 30-39 years; $\longrightarrow-, 40-49$ years; $\longrightarrow, 50-59$ years) at baseline: age and period effects (with fixed cohort). Values are means with their $95 \%$ confidence limits $(C L)$ represented by vertical bars; each line represents data from one cohort

\section{Discussion}

In the present study, age, period and cohort effects on BMI were studied. One of the main findings of the present study was that the apparent decline in BMI with ageing in the oldest group of men seen in the crosssectional analysis was shown to be an artefact due to a cohort effect. When evaluating longitudinal data, BMI still increased in the oldest age group, in both men and women. Furthermore, increase in BMI was greatest in the youngest age group, and the BMI of younger cohorts was higher than that of older birth cohorts at any given age between 30 and 60 years. Although the mean BMI of higher educated persons was lower than the mean BMI of lower educated persons, the increase in BMI with ageing was in general similar for different levels of education.

The tendency for younger adults to have large increases in BMI is confirmed by other studies ${ }^{(3,21,25)}$. Given the already higher BMI levels in the younger cohort, this steep increase in weight will definitely result in an

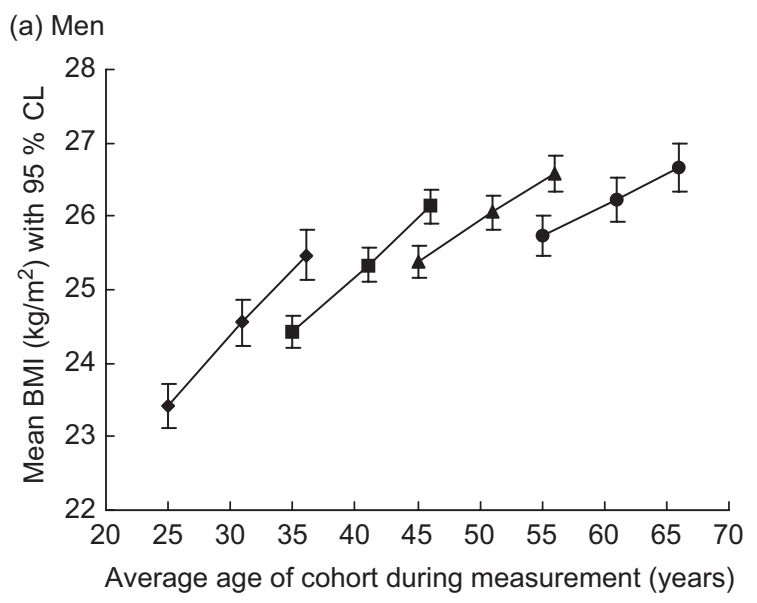

(b) Women

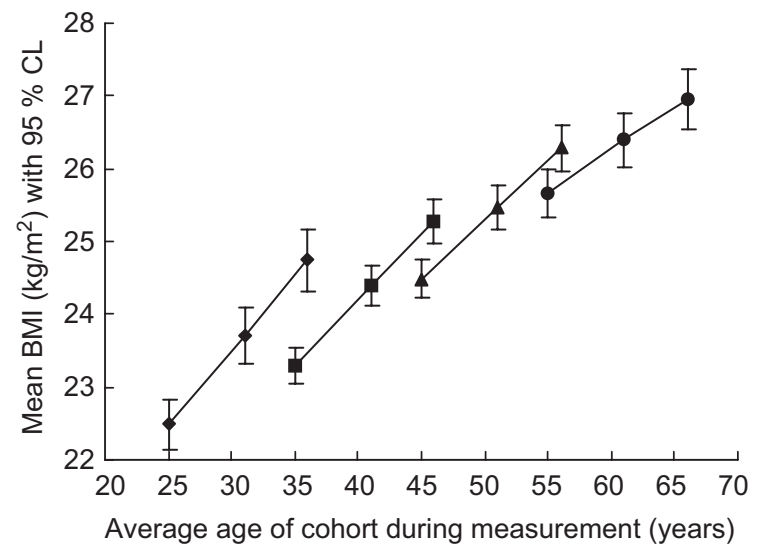

Fig. 3 Longitudinal data of (change in) BMI in men (a) and women (b) by age groups ( $\multimap$, 20-29 years; $\multimap-$, 30-39 years; $\multimap-, 40-49$ years; $\multimap-, 50-59$ years) at baseline: age and period effects (with fixed cohort). Values are means with their $95 \%$ confidence limits $(\mathrm{CL})$ represented by vertical bars; each line represents data from one cohort

increased prevalence of overweight and obesity over time in young adults. Prevention of weight gain in young adult, and also earlier in life, is therefore important for public health.

Contrary to our study, some previous longitudinal studies have observed an apparent decrease in body weight or BMI after age $55-65$ years $^{(3,21,26,27)}$. A possible explanation for differences in results between these studies and the current study could be that the Doetinchem cohort was born at least two decades later than those analysed in the previous studies. It may be that cohorts born earlier than the cohort analysed in the present paper actually did lose weight after age 55-65 years, in contrast to more recently born cohorts, where (positive) cohort and/or period effects were possibly larger than the (negative) effects of ageing per se. This hypothesis is strengthened by results of two recent studies, in which no decline in BMI was observed in both men ${ }^{(18,19)}$ and women $^{(18)}$, although decline after age 70 years was observed in African-American men ${ }^{(18)}$. 
(a) Men

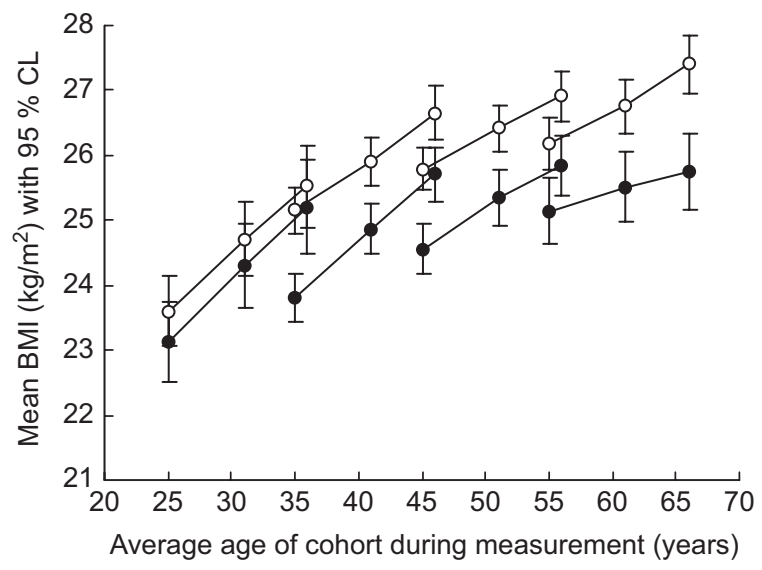

(b) Women

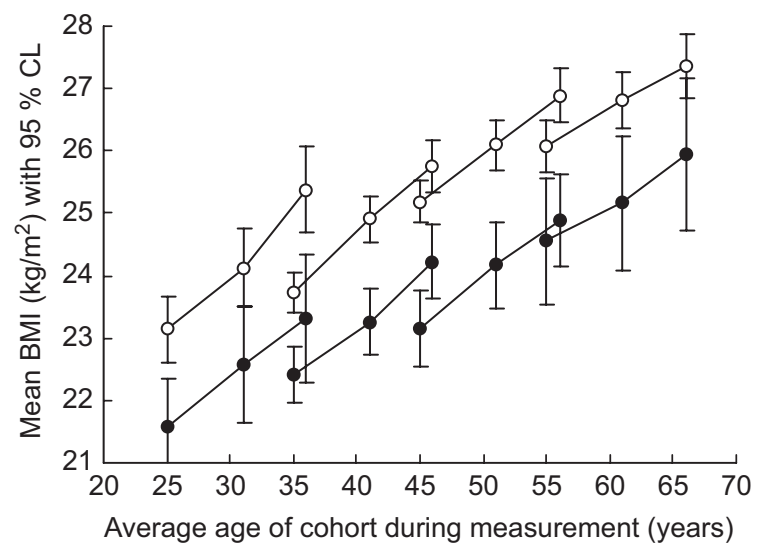

Fig. 4 Longitudinal data of (change in) BMI with age in men (a) and women (b) by age group at baseline, stratified by educational level ( $-\ldots$, low; $\multimap-$, high); note that moderate level of education is omitted from the graphs for reasons of clarity. Values are means with their 95\% confidence limits (CL) represented by vertical bars; each line represents data from one cohort. $\mathrm{BMI}$ of the groups with moderate level of education was always in between the BMl of the groups with low and high level of education
No differences in secular trends of BMI were observed between groups of different educational levels or between never-smokers and the overall group. Similar findings were observed among young adults in the CARDIA cohort ${ }^{(10)}$. Although BMI was higher in lower educated subjects, changes in BMI over follow-up were in general similar to those of higher educated subjects. These findings suggest that differences in BMI due to differences in the educational level particularly occur before adulthood and that prevention of weight gain in adults should also include people with relatively high levels of education. Moreover, results of the present study suggest that also differences in absolute levels of BMI among young adult men may have disappeared over the past decades. The observed higher increase in BMI over follow-up among lower educated men aged 50-59 years at baseline can be explained by the effects of retirement: men who retire from active jobs (in general lower educated) gain more weight after retirement than men who retire from sedentary jobs (with, in general, a higher education) ${ }^{(28)}$.

Results of our cross-sectional analyses in men (but not in women) confirmed results of previous cross-sectional studies, which showed that mean BMI declines after the age of 60 years $^{(1-3)}$. At least three explanations can be given for observing decreasing BMI with ageing in crosssectional studies: selective survival, cohort effect or weight loss after the age of 60 years $^{(4)}$. Because subjects were only included in the present study if they had participated in all three surveys, selective survival did not affect our results. Our longitudinal analyses showed that mean body weight and BMI still increased in subjects over 60 years of age. Results of the present study therefore suggest that the relationship between age and BMI based on cross-sectional data is underestimated because of cohort effects. With a difference of more than one BMI unit over an 11-year period, this underestimation was largest in young adults.

Table 3 Effects of age and period (cross-sectional) and effects of age and cohort (longitudinal) on BMI in men and women

\begin{tabular}{|c|c|c|c|c|c|c|c|c|c|c|c|c|}
\hline & \multicolumn{6}{|c|}{ Men } & \multicolumn{6}{|c|}{ Women } \\
\hline & \multicolumn{3}{|c|}{ Cross-sectional } & \multicolumn{3}{|c|}{ Longitudinal } & \multicolumn{3}{|c|}{ Cross-sectional } & \multicolumn{3}{|c|}{ Longitudinal } \\
\hline & $\beta$ & SE & $P$ value & $\beta$ & SE & $P$ value & $\beta$ & SE & $P$ value & $\beta$ & SE & $P$ value \\
\hline Age (years) & 0.230 & 0.015 & $<0.001$ & 0.297 & 0.014 & $<0.001$ & 0.035 & 0.060 & 0.559 & 0.287 & $0 \cdot 017$ & $<0.001$ \\
\hline Age $\times$ age $\left(\right.$ year $\left.^{2}\right)$ & -0.002 & 0.000 & $<0.001$ & -0.002 & 0.000 & $<0.001$ & 0.001 & 0.001 & 0.173 & -0.001 & 0.000 & $<0.001$ \\
\hline Period $1^{*}$ & \multicolumn{2}{|c|}{ Reference } & - & & & & \multicolumn{2}{|c|}{ Reference } & - & & & \\
\hline Period2 & 0.386 & 0.051 & $<0.001$ & & & & $1 \cdot 519$ & 0.427 & $<0.001$ & & & \\
\hline Period3 & 0.801 & 0.078 & $<0.001$ & & & & $3 \cdot 158$ & 0.773 & $<0.001$ & & & \\
\hline Age $\times$ Period 1 & & - & - & & & & Refer & ence & - & & & \\
\hline Age $\times$ Period 2 & & - & - & & & & -0.027 & 0.010 & 0.006 & & & \\
\hline Age $\times$ Period 3 & & - & - & & & & -0.053 & 0.017 & 0.002 & & & \\
\hline Cohort1t & & & & $2 \cdot 012$ & 0.229 & $<0.001$ & & & & $2 \cdot 111$ & 0.285 & $<0.001$ \\
\hline Cohort2 & & & & $1 \cdot 254$ & 0.193 & $<0.001$ & & & & 0.973 & 0.243 & $<0.001$ \\
\hline Cohort3 & & & & 0.754 & $0 \cdot 190$ & $<0.001$ & & & & 0.538 & 0.240 & 0.025 \\
\hline Cohort4 & & & & Refer & nce & - & & & & Refer & nce & - \\
\hline
\end{tabular}

*Period 1 = baseline; Period $2=6$ years follow-up; Period $3=11$ years follow-up.

+Cohort $1=20-29$ years at baseline; Cohort2 $=30-39$ years at baseline; Cohort $3=40-49$ years at baseline; Cohort $4=50-59$ years at baseline 
(a) Men

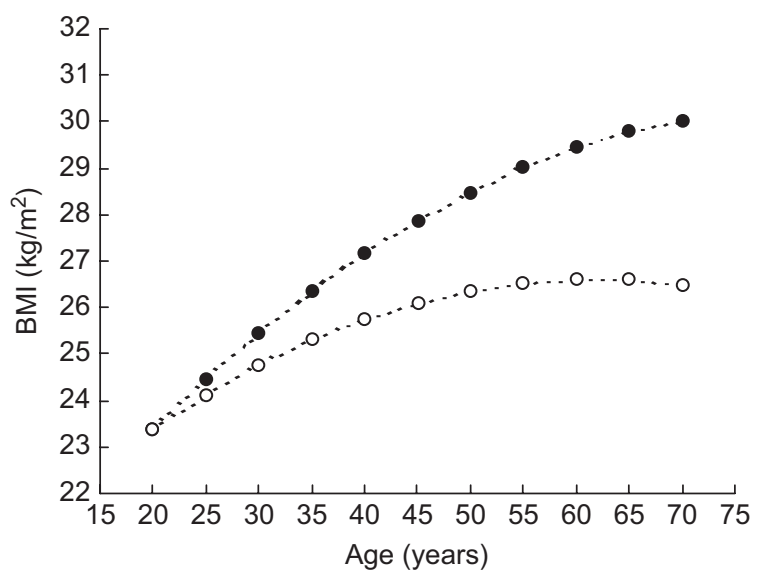

(b) Women

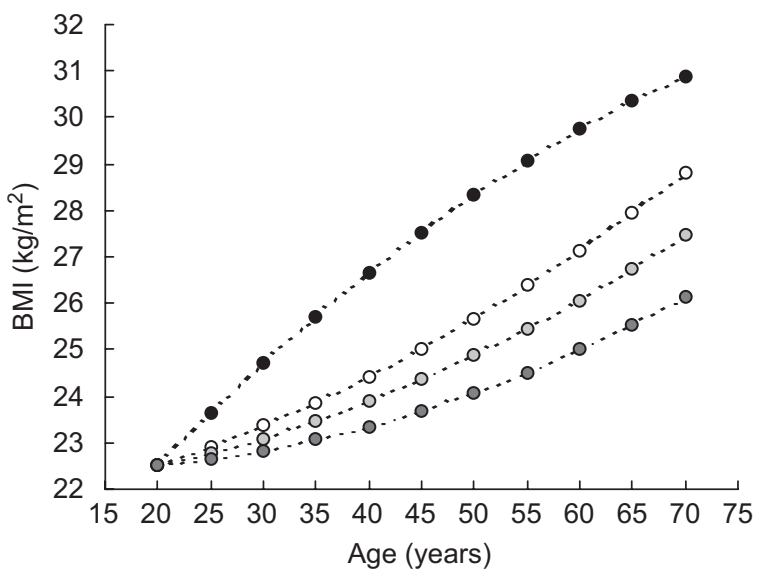

Fig. 5 Mean BMI by age for men (. . . • . . ., longitudinal approach; ...- o. - ., cross-sectional approach) (a) and women (-......, longitudinal approach; $-0-$, cross-sectional $t=0 ; \ldots$. . . , cross-sectional $t=6$; . . o o. . , cross-sectional $t=11$ ) (b), based on random intercept models, taking into account period (crosssectional approach) and cohort effects (longitudinal approach)

Probably the most important drawback of the present study is the dropout of participants during follow-up, which is inherent to longitudinal studies. No information on the level of education, BMI or lifestyle behaviours is available from non-participants at baseline. During the second and the third measurements of the DCS, responders have been compared to the non-responders with respect to several variables ${ }^{(29,30)}$. Compared to responders, non-responders were younger, more often lower educated, obese and smokers. Although the increase in BMI was highest in younger persons, the present study has shown that the age effect on BMI was, in general, similar for different levels of education. Ad hoc analyses showed that overweight and obese women at baseline increased more in BMI over follow-up than normalweight female participants at baseline. For men, no effect of overweight was observed on future weight gain. Also, smoking status at baseline did not predict future weight gain. Taken together, this implies that if the results of the present study are biased by selective dropout, this bias would have led to an underestimation of the age effects on BMI.

Due to the relatively short follow-up period with only three measurements in the present study, we were not able to draw firm conclusions about period effects on BMI. However, we were predominantly interested in age effects on BMI. Effects of period and cohort were used to make the difference between the cross-sectional and the longitudinal approach.

One of the most important advantages of the present study was that body weight was not self-reported, but measured. Next, subjects over a large adult age range (20-59 years at baseline) were included in the study and followed over an 11-year period, including three measurement periods.

Some have argued that prevention of weight gain is not important in older adults, but should be directed to young adults $^{(31)}$. We have argued before that weight gain prevention at older age is still important in preventing adverse health outcomes ${ }^{(32)}$, since weight gain in this age group is progressively related to higher absolute risk for disease and mortality ${ }^{(4,33-39)}$. Because of the combination of higher prevalence of overweight and the observed weight gain at older age, prevention of weight gain at older age results in health gain in the short term. In addition, it has been shown that also percentage body fat increases with ageing until age 80 years, again with higher increases in later birth cohorts ${ }^{(40)}$. As a result, increased prevalence of adverse health outcomes can be expected for the future.

In conclusion, findings of the present study using longitudinal data suggest that findings based on crosssectional surveys underestimate the actual increase in BMI with ageing. This is due to cohort effects. Highest weight gain was observed in young adults, but weight gain was still present after the age of 60 years. Furthermore, weight gain was observed in all age groups and was independent of the level of education. This implies that prevention of weight gain should follow a population-wide, life-course approach.

\section{Acknowledgements}

Sources of funding: The Doetinchem Cohort Study was financially supported by the Ministry of Health, Welfare and Sport of The Netherlands and the National Institute for Public Health and the Environment. The present study is funded by The Netherlands Heart Foundation (No. 2000Z002).

Conflicts of interest: There were no conflicts of interest. Authorship responsibilities: A.C.J.N., J.C.S., T.L.S.V., A.J.S. and W.v.M. came up with the idea for the analyses. A.J.C.N. conducted the analyses. H.C.B. is the statistical consultant. W.M.M.V. is the project director of the 
Doetinchem Cohort Study. All co-authors contributed in interpretation of the results and in writing the manuscript.

Acknowledgements: The authors thank the epidemiologists and field workers of the Municipal Health Service in Doetinchem for their contribution to the data collection for the present study. Project director is Dr W.M.M. Verschuren. Logistic management was provided by J. Steenbrink and P. Vissink, and administrative support by E.P. van der Wolf. Data management was provided by A. Blokstra, A.W.D. van Kessel and P.E. Steinberger. The present study is part of the multidisciplinary NHF-NRG research program. The program committee of this program consists of professors H.C.G. Kemper, F.J. Kok, D. Kromhout (chair) and W.H.M. Saris. Principal investigators are professors J. Brug, W. van Mechelen, E.G. Schouten, J.C. Seidell, and doctors M.A. van Baak, M.J.M. Chin A. Paw, A.J. Schuit, and the projectcoordinators S.P.J. Kremers and T.L.S. Visscher (NHF-NRG, Netherlands Heart Foundation - Netherlands Researchprogramme weight Gain prevention).

\section{References}

1. Seidell JC, Verschuren WMM \& Kromhout D (1995) Prevalence and trends of obesity in The Netherlands 1987-1991. Int J Obes Relat Metab Disord 19, 924-927.

2. Ogden CL, Fryar CD, Carroll MD \& Flegal KM (2004) Mean body weight, height, and body mass index, United States 1960-2002. Adv Data 347, 1-17.

3. Williamson DF, Kahn HS, Remington PL \& Anda RF (1990) The 10-year incidence of overweight and major weight gain in US adults. Arch Intern Med 150, 665-672.

4. Seidell JC \& Visscher TLS (2000) Body weight and weight change and their health implications for the elderly. Eur J Clin Nutr 54, S33-S39.

5. Bielicki T, Szklarska A, Welon Z \& Rogucka E (2001) Variation in body mass index among Polish adults: effects of sex, age, birth cohort, and social class. Am J Phys Anthropol 116, 166-170.

6. Rosengren A, Eriksson H, Larsson B et al. (2000) Secular changes in cardiovascular risk factors over 30 years in Swedish men aged 50: the study of men born in 1913, 1923, 1933 and 1943. J Intern Med 247, 111-118.

7. Midthjell K, Kruger Ø, Holmen J et al. (1999) Rapid changes in the prevalence of obesity and known diabetes in an adult Norwegian population. The Nord-Trøndelag Health Surveys: 1984-1986 and 1995-1997. Diabetes Care 22, 1813-1820.

8. Lahti-Koski M, Jousilahti P \& Pietinen P (2001) Secular trends in body mass index by birth cohort in eastern Finland from 1972 to 1997. Int J Obes Relat Metab Disord 25, 727-734.

9. McTigue KM, Garrett JM \& Popkin BM (2002) The natural history of the development of obesity in a cohort of young US adults between 1981 and 1998. Ann Intern Med 136, 857-864.

10. Lewis CE, Jacobs DR Jr, McCreath H et al. (2000) Weight gain continues in the 1990s: 10-year trends in weight and overweight from the CARDIA study. Coronary Artery Risk Development in Young Adults. Am J Epidemiol 151, 1172-1181.

11. Gutierrez-Fisac JL, Banegas-Banegas JR, Artalejo FR \& Regidor E (2000) Increasing prevalence of overweight and obesity among Spanish adults, 1987-1997. Int J Obes Relat Metab Disord 24, 1677-1682.
12. Bendixen H, Holst C, Sorensen TI, Raben A, Bartels EM \& Astrup A (2004) Major increase in prevalence of overweight and obesity between 1987 and 2001 among Danish adults. Obes Res 12, 1464-1472.

13. Lindström M, Isacsson SO \& Merlo J (2003) Increasing prevalence of overweight, obesity and physical inactivity: two population-based studies 1986 and 1994. Eur J Public Health 13, 306-312.

14. Flegal KM, Carroll MD, Kuczmarski RJ \& Johnson CL (1998) Overweight and obesity in the United States: prevalence and trends, 1960-1994. Int J Obes Relat Metab Disord 22, 39-47.

15. Flegal KM, Carroll MD, Ogden CL \& Johnson CL (2002) Prevalence and trends in obesity among US adults, 1999-2000. JAMA 288, 1723-1727.

16. Lewis CE, Smith DE, Wallace DD, Williams OD, Bild DE \& Jacobs DR Jr (1997) Seven-year trends in body weight and associations with lifestyle and behavioral characteristics in black and white young adults: the CARDIA study. Am J Public Health 87, 635-642.

17. Portrait F, Alessie RJM \& Deeg D (2002) Disentangling the Age, Period, and Cohort Effects using a Modeling Approach. Discussion Paper TI, 02-120/3. Amsterdam: Tinbergen Institute; available at http://www.tinbergen.nl/ discussionpapers/02120.pdf

18. Stevens J, Jones DW \& Arnett D (2003) Associations of aging and birth cohort with body mass index in a biethnic cohort. Obes Res 11, 426-433.

19. Barone BB, Clark JM, Wang N-Y, Meoni LA, Klag MJ \& Brancati FL (2006) Lifetime weight patterns in male physicians: the effects of cohort and selective survival. Obesity 14, 902-908.

20. Burke GL, Bild DE, Hilner JE, Folsom AR, Wagenknecht LE \& Sidney S (1996) Differences in weight gain in relation to race, gender, age and education in young adults: the CARDIA Study. Coronary Artery Risk Development in Young Adults. Ethn Health 1, 327-335.

21. Sheehan TJ, DuBrava S, DeChello LM \& Fang Z (2003) Rates of weight change for black and white Americans over a twenty year period. Int J Obes Relat Metab Disord 27, 498-504.

22. Verschuren WMM, Smit HA, van Leer EM et al. (1994) Prevalence and Risk Factors of Cardiovascular Disease and their Changes in the Period 1987-1991. Final Report Monitoring Project on Cardiovascular Disease Risk Factors 1987-1991 (in Dutch). Bilthoven: National Institute of Public Health and Environmental Protection.

23. Verschuren WMM, Blokstra A, Picavet HSJ \& Smit HA (2008) Cohort Profile: The Doetinchem Cohort Study. Int J Epidemiol (Epublication ahead of print version).

24. Smit HA, Verschuren WMM, Bueno de Mesquita HB \& Seidell JC (1994) The Monitoring Project on Risk Factors for Chronic Diseases in the Netherlands (MORGEN-Project): Aim and Method (in Dutch). Bilthoven: National Institute of Public Health and the Environment.

25. Rissanen A, Heliövaara M \& Aromaa A (1988) Overweight and anthropometric changes in adulthood: a prospective study of 17,000 Finns. Int J Obes 12, 391-401.

26. Shimokata H, Tobin JD, Muller DC, Elahi D, Coon PJ \& Andres R (1989) Studies in the distribution of body fat: I. Effects of age, sex, and obesity. J Gerontol 44, M66-M73.

27. Friedlænder JS, Costa PT Jr, Bosse R, Ellis E, Rhoads JG \& Stoudt HW (1977) Longitudinal physique changes among healthy white veterans at Boston. Hum Biol 49, 541-558.

28. Nooyens ACJ, Visscher TLS, Schuit AJ et al. (2005) Effects of retirement on lifestyle in relation to changes in weight and waist circumference in Dutch men: a prospective study. Public Health Nutr 8, 1266-1274.

29. Blokstra A \& Verschuren WMM (2002) De Doetinchem Cohort Studie, Voortgangsrapportage over de periode 
1998-2001 (in Dutch). Bilthoven: National Institute of Public Health and the Environment.

30. Blokstra A, Smit HA \& Verschuren WMM (2006) Veranderingen in leefstijl- en risicofactoren voor chronische ziekten met het ouder worden: De Doetinchem Studie 1987-2002 (in Dutch). Bilthoven: National Institute of Public Health and the Environment.

31. Gostynski M, Gutzwiller F, Kuulasmaa K et al. (2004) Analysis of the relationship between total cholesterol, age, body mass index among males and females in the WHO MONICA Project. Int J Obes Relat Metab Disord 28, 1082-1090.

32. Seidell JC, Nooyens AJ \& Visscher TL (2005) Cost-effective measures to prevent obesity: epidemiological basis and appropriate target groups. Proc Nutr Soc 64, 1-5.

33. Peters ET, Seidell JC, Menotti A et al. (1995) Changes in body weight in relation to mortality in 6441 European middle-aged men: the Seven Countries Study. Int J Obes Relat Metab Disord 19, 862-868.

34. Wannamethee SG, Shaper AG \& Walker M (2005) Overweight and obesity and weight change in middle aged men: impact on cardiovascular disease and diabetes J Epidemiol Commun Health 59, 134-139.

35. Colditz GA, Willett WC, Rotnitzky A \& Manson JE (1995) Weight gain as a risk factor for clinical diabetes mellitus in women. Ann Intern Med 122, 481-486.

36. Barnett JB (2003) The relationship between obesity and breast cancer risk and mortality. Nutr Rev 61, 73-76.

37. Radimer KL, Ballard-Barbash R, Miller JS et al. (2004) Weight change and the risk of late-onset breast cancer in the original Framingham cohort. Nutr Cancer 49, 7-13.

38. Taylor EN, Stampfer MJ \& Curhan GC (2005) Obesity, weight gain, and the risk of kidney stones. JAMA 293, 455-462.

39. Koh-Banerjee P, Wang Y, Hu FB, Spiegelman D, Willett WC \& Rimm EB (2004) Changes in body weight and body fat distribution as risk factors for clinical diabetes in US men. Am J Epidemiol 159, 1150-1159.

40. Ding J, Kritchevsky SB, Newman AB et al. (2007) Effects of birth cohort and age on body composition in a sample of community-based elderly. Am J Clin Nutr $\mathbf{8 5}$, 405-410. 